\title{
THE EFFECTS OF METALLIC SALTS ON THE HISTOLOGY AND FUNCTIONING OF THE RAT TESTIS
}

\author{
M. J. HOEY \\ Department of Anatomy, University of Liverpool
}

(Received 10th February 1966)

\begin{abstract}
Summary. A series of experiments was carried out to determine the effect of five metals on the histology and functioning of the testis and epididymis in rats. The metals (silver, copper, tin, nickel and cobalt) were administered subcutaneously as aqueous salts in a single dose or as daily injections from 1 to 30 days; the testes were then subjected to normal histological examination and dark ground microscopy, and to radiography following intra-arterial injection of Micropaque in one experiment.

All five metals produced acute and chronic changes in the histology of the testis and interfered, to some degree, with spermatogenesis. All tissues showed improvement following the initial injection, even in spite of continued daily injections. The individual results are described in detail.

The effects and possible modes of action of these metals are discussed and contrasted with cadmium. It would appear that all the metals investigated act in a different way from cadmium, and may in fact limit their own action by precipitating proteins in the membrana propria, thus making it impermeable to further metallic ions. It is possible that the action of the metals on the epididymis varies from that on the testis, and the damage produced in the epididymis and ductuli efferentes shows less tendency to recover.
\end{abstract}

\section{INTRODUCTION}

Since Parizek first investigated the effects of cadmium on the histology and functioning of the testis in 1956, much work has been done on the various aspects of its action by Pařizek and others.

Relatively little work has been published on metals with a similar chemical activity to cadmium in their action on the testis. Kamboj \& Kar (1964) investigated a large number of metallic and rare earth salts, and some aspects have been recorded of the effects of lithium (Macleod, Swan \& Aitken, 1949) and selenium (Maekawa, Tsunenari \& Kurematsu, 1965).

It would appear necessary, therefore, to make a thorough investigation of the action of metallic salts, closely related to cadmium in the Periodic Table, on testicular and associated tissues, and spermatogenesis. In the present work silver, copper, tin, nickel and cobalt salts are investigated. 


\section{MATERIALS AND METHODS}

Male albino rats, selected at random, were used. They were housed under identical conditions for the duration of the experiments, and killed by means of an overdose of chloroform.

The testes were removed at death and fixed in Bouin's solution (unless otherwise indicated in the description of the experiments). Serial sections of the upper half of the testis, the rete testis, ductuli efferentes, ductus deferens and the head and body of the epididymis were prepared and stained by means of iron haematoxylin and eosin. Unstained sections were also prepared to permit of dark ground microscopy.

Aqueous solutions of the salts of five metals, namely silver nitrate, copper sulphate, nickel sulphate, cobalt chloride and stannous chloride were administered by subcutaneous injection, the dose being $0.04 \mathrm{~m}-\mathrm{mole} / \mathrm{kg}$ body weight. Any variation or addition to this procedure will be described with the relevant experiment.

The following experiments were performed:

(1) Five rats weighing from 160 to $170 \mathrm{~g}$ were used. Each rat was injected, according to weight, with a different metal. The rats were then killed $18 \mathrm{hr}$ after injection and the testes removed and treated as above.

(2) Five groups of rats, with four rats in each group, weighing from 129 to $200 \mathrm{~g}$, were given daily injections of one metal. A rat from each group was killed at 2, 10, 21 and 30 days, respectively, after the first injection.

(3) Five groups of rats, three rats in each group, weighing from 206 to 270 $\mathrm{g}$, were given a single injection of one metal. A rat from each group was killed 4,8 and 12 days after injection respectively.

(4) Five groups of three rats, weighing from 140 to $315 \mathrm{~g}$, were given ten daily injections of one metal. A rat from each group was killed the day after injections ceased, then one on the 4th and one on the 8th day.

(5) Five rats, weighing from 120 to $156 \mathrm{~g}$, were injected with one of the metals. Twenty-four hours later each rat was anaesthetized, the thoracic cage was opened to expose the thoracic aorta, and $25 \mathrm{ml}$ of Micropaque (Damancy \& Co.) were injected into the aorta, which was then ligated. The testes were removed and X-rayed, using Kodak RS 5 plates.

Tubular diameters were calculated as the mean of the shorter diameter of a random sample of not less than fifty tubules.

\section{RESULTS}

At the outset of the experiments it was found that there was uniformity of results and the sequential changes observed demonstrated a progressive series. It was, therefore, considered unnecessary to repeat the experiments using more animals.

Every set of experiments produced changes in the testis and adnexa. To the naked eye the testes appeared normal in size and colour as regards the tissue itself, but hyperaemia was more or less marked in all cases, and those specimens 
exhibiting pronounced hyperaemia frequently had small punctate haemorrhages in the fatty body.

The various histological changes will be described in detail and the individual results will then be related to these changes.

\section{ACUTE CHANGES}

These were manifest in Experiment 1.

The most marked change is shrinkage of the tubules, particularly the more centrally placed ones (mean diameter $=16.9 \mu$ ), to give wide spaces between the tubules in which the isolated interstitial tissue is found. The peripheral tubules retain their normal diameter (mean diameter $=19.3 \mu$ ), and though the depth of these normal tubules varies from one to four, the area is generally uniform around the testis (Pl. 1, Fig. 1).

Eosinophilic oedema fluid is always present in the spaces and is most marked in the peripheral area. There is a great increase in the lymphatic drainage, all the vessels being grossly enlarged, and in some cases they contain the breakdown products of haemoglobin. Similarly there is hyperaemia with marked engorgement of the intertubular capillaries, and of the testicular veins particularly.

Within the tubules the damage varies in extent, being most marked in the central tubules. Many of these are grossly shrunken (to as little as $14 \mu$ in diameter) and have their central lumen entirely obliterated, whilst the tubular tissue is darkly stained and the cells no longer well differentiated. Gradation of damage from this to normal occurs and in some tubules, commonly the central ones, groups of cells undergoing mitosis are visible (Pl. 1, Fig. 2).

The interstitial tissue shows considerably less damage than the tubules at this stage. It is normal in amount and may be quite normal structurally. Where damage does occur the nuclei of the Leydig cells show thickening of the nuclear membrane and clumping of the chromatin and, when present, the damage occurs throughout the whole testis (Pl. 1, Fig. 3).

Spermatogenesis does not appear to be affected, apart from increased nuclear basophilia of spermatogonia and Sertoli cells. The formed spermatozoa, however, frequently show separation of the head and some tubules have a ring of tailless, pyknotic sperm heads around the lumen. The condition of the spermatozoa in the epididymis varies from normal to quite degenerated.

The ductuli efferentes show marked damage, with considerable epithelial proliferation, and areas of complete blockage. This can be seen to produce some enlargement of the proximal ductuli and of the rete testis (Pl. 1, Fig. 4).

Changes in the epididymis vary from negligible to marked, particularly in the head of the epididymis which may contain shrunken and distorted tubules showing patchy secretory activity (Pl. 1, Fig. 5).

\section{Experiment 1}

This showed the acute changes occurring $18 \mathrm{hr}$ after a single injection.

Silver. This will be taken as the standard metal for comparison with other metals. Silver, in fact, produced marked damage to all the tissues; even the 
peripheral tubules were affected, and some central tubules had completely disintegrated, leaving a space ringed by interstitial tissue, which also showed damage. There was very marked deformation of the tubules in the head of the epididymis, whose epithelial cells appear swollen because of the tubular shrinkage.

Copper. Copper shows the same range of damage but to a lesser degree, and a normal peripheral band, four tubules deep, remains. The head of the epididymis is relatively normal, apart from the secretory activity. This metal causes spermatogenic damage of the nature described above in the central third of the testis.

Tin. Tin resembles silver closely, but cellular differentiation is retained. Interstitial tissue damage is greater than with copper. Epididymal damage resembles copper, but the spermatozoa here are markedly degenerate.

Nickel. This resembles silver without the interstitial damage. There is some shrinkage of the epididymal tubules but their regular shape is retained. The spermatozoa in the epididymis are completely degenerated.

Cobalt. Cobalt has no effect on the interstitial tissue but the deformation of the epididymal tubules resembles silver. Spermatogenesis is as active as with silver, but abnormal heads are more predominant.

Dark ground microscopy in all cases shows that the metal is present in the interstitial tissue, the lumina of all the tubules (in the spermatozoa), sometimes in the tissue of the peripheral tubules, and in the spermatozoal contents of the epididymis. Occasionally it occurs in the tunica albuginea. Copper occurs in smaller quantities than silver, as does nickel. Tin is present in similar amounts to silver, and cobalt is intermediate between the two groups.

\section{GHRONIC CHANGES}

These were seen in Experiments 2, 3 and 4. In most cases the predominant tendency is for the tissues either to recover or to deteriorate, but both processes may occur in the same testis: some tubules regaining a normal appearance whilst neighbouring tubules degenerate completely.

In the process of recovery the normal tubular size is regained and cell differentiation becomes complete. The lymphatic drainage resumes normal proportions, but it is of interest that, even when the cellular appearance is normal, oedema fluid is still to be found, particularly between the peripheral tubules. Also, the recovery of testicular structure does not necessarily denote a return to normal spermatogenesis and vice versa (see below).

Two distinct types of degeneration occur. The more severe type is an extension of the acute changes. The tubules become more shrunken (to as little as $9 \cdot 6 \mu$ in diameter) and darkly staining, individual spermatogenic cell types becoming indistinguishable, the nuclei of primary spermatocytes undergoing karyorrhexis and the nuclei of other cell types, apart from Sertoli cells, showing karyolysis. Finally, a more or less homogenous mass results, which is ultimately absorbed or disappears, leaving a space ringed by interstitial tissue. This would appear to be a slower version of the tubular disappearance seen in the acute changes (Pl. 1, Fig. 6). 
The less severe degeneration appears to start with single or multiple vacuolation in the tubular tissues, due to isolated death of primary spermatocytes or of Sertoli cell nuclei (Pl. 1, Fig. 7). The damage progresses to a stage at which there is fragmentation of tubular contents (Pl. 2, Fig. 8). This effect appears to be produced by the disintegration of the Sertoli cell cytoplasm. The Sertoli cell nuclei appear swollen and granular and, in places, can be seen being extruded through the membrana propria, often in large numbers (Pl. 2, Fig. 9). The remaining cells in the seminiferous tubules are normal, and groups of them can be seen to undergo mitosis.

The spermatozoa, lying in the tubular lumina in this last group are usually so markedly damaged as to be a homogenous mass. Pyknotic sperm heads are seen in some tubules, commonly ringing the lumen, and devoid of tails. Normal sperm heads, again tailless, occur, lying radially in the tubular tissue.

Full recovery of the duct systems seldom occurs. In almost all cases the ductuli efferentes show marked damage, amounting to blockage of the duct lumen. This can lead to very marked dilatation of the rete testis and proximal ductuli, and collapse of the distal ductuli. The head and body of the epididymis show a more marked ability to recover, necrosis here being rare.

As with Experiment 1, the results of the following experiments will be described with silver as the standard metal. The results of dark ground microscopy will be noted after each experiment.

\section{Experiment 2}

This experiment is an attempt to determine the sequence of events occurring when the testis is exposed to metal over a prolonged period, in this case 30 days.

Silver. After 2 days the changes are similar to those in the acute experiment. A band of peripheral tubules (some four to five tubules deep) appears normal but the central tubules are shrunken (mean diameter $16 \cdot 12 \mu$ ) and some show a slight degree of fragmentation of tissue, between well differentiated cells. Mitotic figures occur throughout the testis. There is some folding of the membrana propria of tubules with both apparent and real extrusion of tubular contents (Pl. 2, Fig. 10). Normal and pyknotic sperm heads are present and the interstitial tissue shows some damage, most marked in central areas. The rete testis shows marked dilation resulting from necrosis and blockage of the ductuli efferentes. One tubule in the head of the epididymis is blocked by necrosis.

At 10 days, improvement has occurred and the tubular diameter is increased (to a mean diameter of $19.11 \mu$ ), whilst the damage to the interstitial tissue is less marked. Little change has occurred in the duct system. Spermatozoal heads are less numerous in the seminiferous tubules and the majority are pyknotic.

At 21 days, the tubular diameter is normal but many tubules show fragmentation and most of these contain no spermatozoa. Spaces indicating tubular disintegration are present. The few tubules which appear normal contain pyknotic heads around their lumina. The interstitial tissue is normal, but oedema fluid is present in large amounts. The epididymal epithelium has breaks in its continuity, but otherwise the duct system shows little change.

By 30 days normal spermatogenesis has been resumed by many tubules. The cellular structure of the tubules is almost normal. The ductuli efferentes 
have recovered to a normal appearance except for a small area very close to the testis. Lymphatic dilatation is diminished although not yet of normal dimensions.

Copper. In the early stages, copper is more destructive than silver. There is no evidence of spermiogenesis, and improvement is less rapid and extensive than with silver. Spermiogenesis improves although it has not fully recovered in $70 \%$ of tubules by 30 days. Necrosis of the ductuli efferentes persists, causing gross dilation of the rete testis.

Tin. This produces a more severe chronic damage very rapidly, and spermiogenesis is almost suppressed in the early stages. Necrosis occurs in the head of the epididymis and the ductuli, and leucocytic infiltration occurs between the tubules. The ductuli efferentes contain oedema fluid (Pl. 2, Fig. 11). By 30 days all tubules display normal spermatogenesis up to and including normal spermatozoa.

Nickel. Nickel produces much less testicular damage in the early stages than silver, but the effect on spermatogenesis is similar. The effect on the duct systems resembles tin. Damage to interstitial tissue and the body of the epididymis increases whilst testicular recovery is occurring, and finally full spermatogenesis is resumed while the ductuli remain necrotic.

Cobalt. Cobalt produces a complete range of chronic damage early, and spermiogenesis is almost completely suppressed. The interstitial tissue is damaged and fragmented in places. Necrosis is present only in the ductuli. Some improvement occurs but the necrosis in the duct system increases, and at 21 days there is still shrinkage of tubules in the central third of the testis and spermiogenesis is only present in $48 \%$ of tubules.

Dark ground microscopy shows a similar appearance with all metals. The metal occurs in the interstitial tissue, and in the spermatozoa in the tubular lumina and epididymis, in almost all cases. It is also marked in the blood and lymphatic vessels. It spreads into the membrana propria, the tunica albuginea and the epididymal epithelium and may be cleared out of these latter tissues. Where fragmentation is occurring, in the seminiferous tubules, the metal lines the tissue spaces, so appearing to be present in the tubular tissues. A constant feature at 21 days is the apparent swelling of the membrana propria which although showing little metal appears as a wide shadow (Pl. 2, Figs. 12 and 13).

\section{Experiment 3}

This was designed to determine the extent of recovery over a period following a single injection.

Silver. At 4 days, the damage present is much less than at any stage in Experiment 2. Small areas of fragmentation occur in a few central tubules, and normal spermiogenesis is occurring in $60 \%$ of tubules, although some pyknotic heads are being produced. There is very marked dilation of the lymphatics, and oedema fluid is present in large quantities. Proliferation of the ductuli efferentes has occurred and the epididymal spermatozoa show degeneration.

At 8 days, some of the testicular tubules show severe chronic damage and others have patches of damaged tissue. The oedema fluid is diminished and the lymphatics are therefore not as dilated. Spermiogenesis has decreased, 
being present in only $24 \%$ of tubules, and a greater proportion of pyknotic heads is present. The ductuli efferentes show necrosis.

At 12 days, mild chronic damage persists and oedema fluid is still quite prominent. Spermiogenesis is still suppressed, occurring in $62 \%$ of tubules and only the peripheral tubules show normal activity. Pyknotic sperm heads are in the majority. The interstitial tissue is normal. Necrosis persists in the ductuli with resultant proximal swelling. The epididymis is normal.

Copper. This produces much more severe chronic damage than silver, and normal spermiogenesis occurs in only $30 \%$ of tubules. Necrosis extends into the head of the epididymis as well as the ductuli. Improvement in testicular tissue occurs, but there is only a $10 \%$ improvement in spermiogenesis, and necrosis persists in the duct system.

Tin. Initially this resembles copper but spermiogenesis recovers to a greater extent. Necrosis persists in the ductuli and the epithelial cells of the epididymis are interrupted. Finally, however, the central tubules do not recover full spermiogenesis.

Nickel. Nickel closely resembles silver but spermiogenesis is more severely affected in the early stages, being present in only $16 \%$ of tubules, and the condition of the tissues regresses until spermiogenesis has virtually ceased $(4 \%)$. Some recovery occurs finally, but spermiogenesis remains very limited.

Cobalt. Initially cobalt resembles silver, but necrosis in the ductuli efferentes becomes marked. Spermiogenic activity remains normal throughout.

Dark ground microscopy shows that the metals are present in the same situations as in Experiment 1. Copper is present in smaller quantities than the other metals. At 8 and 10 days the amount of metal present appears to increase.

\section{Experiment 4}

This experiment shows the extent of damage and recovery of tissue after a short course of injections.

Silver. At 4 days the histology is nearly normal. Spermiogenesis is occurring in all tubules but many pyknotic heads are present. There is slight interstitial damage and necrosis occurs in the ductuli efferentes.

At 8 days, the overall picture has regressed, with marked degeneration of the central tubules and tissue breakdown in the others. The amount of oedema fluid has increased. Spermiogenesis only occurs in the outermost tubules. Interstitial damage has increased, and in the duct system necrosis is more pronounced and the epididymal epithelium is broken down.

By 12 days recovery has taken place and the picture resembles that at 4 days. Spermiogenesis is more active centrally, and is normal at the periphery. Necrosis persists in the ductuli, and damage to the epididymis is unchanged.

Copper. Copper produces, at 4 days, some mild chronic damage to tubular tissues and spermiogenesis is much reduced. Necrosis occurs in the ductuli efferentes. The epididymal spermatozoa are almost completely degenerated. Again regression occurs, bringing spermiogenesis to a standstill at 8 days, and the final picture, although showing some improvement, is mainly one of mild chronic damage.

Tin. Initially this resembles copper but, although some tubules regress, many 
show a rapid improvement; spermiogenesis is quite active by 8 days, and finally is almost normal ( $90 \%$ of tubules) although some pyknotic heads are present in a few tubules. The final picture shows very marked hyperaemia and gross dilation of the lymphatics, although the tissues show only mild damage.

Nickel. Nickel has a similar effect to silver, but the suppression of spermiogenesis is far less than with other metals. Necrosis of ductuli is progressive as with other metals, but the testicular tissue and spermatogenesis are virtually normal by 12 days.

Cobalt. This produces only mild testicular damage initially, and spermiogenic activity is good, about half the formed spermatozoa being normal. Hyperaemia is marked, as with tin. Some interstitial damage occurs and the ductuli show necrosis. Regression occurs which is not much improved by 12 days, although spermiogenesis returns almost to normal.

Dark ground microscopy shows the usual variation in distribution within the tissues. Once again copper is present in less quantity, and at the intermediate stage in the results there is an increase in the amount of metal present in the tissues.

\section{Experiment 5}

The results of this experiment are shown in Plate 3.

Silver. This shows clearly the gross enlargement of the lymphatic channels, and the hyperaemia leading to haemorrhages into the fatty body. The vessels displayed in the testis itself are mainly venous.

Copper. Arterial enlargement in the testis is more pronounced and the lymphatic drainage is much less marked than with silver. Haemorrhages are small and scanty.

Tin. Tin combines the properties of both previous metals in its effect. Arteries, veins and lymphatics are all prominent, but haemorrhages are not as marked as with silver.

Nickel. Nickel has a similar but less pronounced effect than tin.

Cobalt. Cobalt is notable for the numerous small haemorrhages throughout the fatty body, although the testicular vessels are not unduly prominent. Lymphatic channels are again much enlarged.

Silver, tin and cobalt show the greatest enlargement of lymphatic channels draining the testis.

\section{DISCUSSION}

Although the histological changes produced by the metals under investigation are basically similar to those produced by cadmium (Pařizek, 1957), they occur to a much lesser degree, and none of these metals produced ultimate necrosis and death of the testicular tissue.

The histological changes in the seminiferous tubules differ from those produced by cadmium, in the mature rat, in the degree of shrinkage which occurs. All five metals produce marked shrinkage of some tubules. The fact that neighbouring tubules remain normal excludes the possibility of an artefact. The 
concentration of all salts used was similar to that of cadmium as used by Pařizek; therefore it would appear that a straightforward osmotic phenomenon is unlikely, but the mode of action could possibly be a manifestation of a Donnan equilibrium across the membrana propria, the membrana being more selective to certain ions. This implies that cadmium may pass across the membrane more readily than the other metals.

Another possibility is that the metals used precipitate proteins, in the membrana propria, more easily than does cadmium, so causing a change in its permeability and achieving their effect by virtue of dehydrating contents of the seminiferous tubules, whilst cadmium may exert a selective toxicity on spermatogenic cells after passing readily through the membrana propria. The concentration of metal in the membrana propria evident in dark ground illumination, together with the swelling apparent in the later stages of Experiment 2, would imply a particular involvement of the membrana.

Both cadmium and other metals probably damage vascular endothelium within the testis, so explaining the increase in interstitial fluid, some of which may be contributed from fluid within the seminiferous tubules in the case of the metals other than cadmium; the changes in vascularity and lymphatic drainage are a logical consequence of this, to remove the excess interstitial fluid. The acute changes in these experiments would seem to be largely due to this mechanism, producing little change in the cellular appearance of the testicular tissue apart from the oedema.

The more prolonged effect of metal administration is interesting in that it produces unmistakable damage to the Sertoli cells. Since these cells are probably responsible for passing nutrition from the membrana propria to the maturing spermatozoa, it is logical that they should be the first cells to be exposed to the metal, and would explain why the spermatozoa, but not the spermatogenic cells, take up the metal so readily. This fact, together with the breakdown and disappearance of the Sertoli cell cytoplasm, is particularly noticeable under dark ground illumination, their position in the tubules being outlined by the metal (Pl. 2, Fig. 12). It is at this stage of Sertoli cell destruction that the membrana propria appears to swell, so it is feasible to hypothesize that the histological improvement commonly seen in the last stage of Experiment 2 may be brought about by the resulting impermeability of the membrana to the metal, so allowing for recovery and regeneration of the Sertoli cells. Since the recovery occurs in spite of continued injections it is obvious that some resistance occurs.

A notable feature of all the metals used is their inability to produce irreversible damage to the testicular tissue. Whereas with cadmium the seminiferous tubules are completely destroyed by a single injection, and the interstitial tissue only shows signs of recovery after 20 days, recovery, to a greater or lesser extent, occurred with all the metals used. However, the degree of damage and recovery with the individual metals varies considerably. Without doubt the metal producing the most lasting damage to both tissues and spermatogenesis, in all the experiments performed, is copper. Silver produces relatively mild damage, and although recovery is not complete in any experiment, it occurs to a considerable degree. Tin and nickel, in general, allow of a good degree of recovery in all cases, despite profound initial damage resulting from tin, and cobalt 
produces long-term damage to both tissues and spermatogenesis, whilst recovery after it is generally good in short-term experiments. It is difficult to postulate any reason for the variety of effects found with these five metals; their $\mathrm{pH}$, molecular size and valency are similar and therefore do not appear immediately to have any particular significance, so their ultimate action in the cells must presumably be a purely chemical one.

Whilst the testicular damage is somewhat variable, the damage to the ductuli efferentes and epididymis seems to be more consistent. It may be noted that the epididymis appears fairly resistant to damage, even when dark ground illumination shows the presence of metal at the base of the epithelial cells. Copper is the only metal consistently causing some necrosis of the head of the epididymis - the others produce proliferation and blockage of the ductuli only.

One significant fact is that in Experiment 4, after a short course of injections, the subsequent damage to the whole of the duct system appears to be progressive to a greater or lesser degree.

The question now arises as to the mode of action of the metals on the duct system. Gunn, Gould \& Anderson (1963) proved that cadmium exerts its overall effect in the territory of distribution of the superior epididymal branch of the testicular artery, and by way of the latter itself. The fact that no damage occurs to the body or tail of the epididymis after administration of cadmium is confirmative. The action of the metals investigated here is most profound on the ductuli efferentes. Their effect on the head of the epididymis, and to a lesser extent on the body, would imply that if a vascular factor is involved it is not as specific as for cadmium. The regenerative processes of the duct system are much slower than those of the spermatogenic tissue, however, presumably owing to its normally lower mitotic rate.

It is also possible that another route of access of metal to the epididymal tissue exists. Since the spermatozoa very rapidly take up the metals in large amounts, it is feasible that some absorption of metal from the spermatozoa by the epithelial cells of epididymis may take place. This being the case it is logical to suppose that the ductuli efferentes would, therefore, absorb the greatest proportion of metal and so sustain the greatest damage.

The acute experiment produces a different effect on the head of the epididymis, namely a severe shrinkage of the tubules seen with cobalt and silver. This damage, which does not occur in the initial segment, has disappeared by the 4th day, as seen in Experiment 3. This is of interest in view of the special histochemical properties of this area (Nicander, 1957).

The epididymal spermatozoa show a great concentration of metal in them under dark ground microscopy, from the first day after injection. This metal content must, therefore, have been absorbed in some other way than by contribution from the Sertoli cells, since the time taken for passage of spermatozoa from the seminiferous tubules amounts to at least 4 days (Macmillan \& Harrison, 1955).

Of the metals investigated here silver, nickel and cobalt (as aqueous salts) were investigated by Kamboj \& Kar (1964) who administered a single subcutaneous injection to rats. They failed to notice any histological change in testis or epididymis by this route of administration at 2 or 7 days. This is not 
in agreement with the results obtained here, since quite profound changes were obtained between 1 and 8 days.

\section{ACKNOWLEDGMENTS}

This investigation was supported financially by the Lalor Foundation, U.S.A. My thanks are also due to Professor R. G. Harrison for allowing me to use the facilities of his Department, and for his interest and advice in this project; to $\mathrm{Mr}$ L. Reeve and Mr D. Ellames for their technical assistance, and to Mr A. St Clair for his help with the preparation of the plates.

\section{REFERENCES}

Gunn, S. A., Gould, T. C. \& Anderson, W. A. D. (1963) The selective injurious response of testicular and epididymal blood vessels to cadmium and its prevention by zinc. Am. F. Path. 42, 685 .

Kamboj, V. P. \& Kar, A. B. (1964) Antitesticular effect of metallic and rare earth salts. F. Reprod. Fert. 7, 21 .

Macleod, J., Swan, R. C. \& Aitken, G. A. (1949) Lithium: its effect on human spermatozoa, rat testicular tissue and upon rats in vivo. Am. F. Physiol. 157, 177.

Macmillan, E. W. \& Harrison, R. G. (1955) The rate of passage of radiopaque medium along the ductus epididymidis of the rat. Stud. Fert. 7, 35,

Maekawa, K., Tsunenari, Y. \& Kurematsu, Y. (1965) The destructive effect of selenium dioxide on the testis of the rat. Acta anat. nippon. 40, 140.

NICANDER, L. (1957) On the regional histology and cytochemistry of the ductus epididymis in rabbits. Acta néerl. morph. $1,99$.

Pařízex, J. (1956) Effect of cadmium salts on testicular tissue. Nature, Lond. 177, 1036.

PAর̌ízek, J. (1957) Kastrace Kadmiem. Státní Zdravotnické Nakladatelství, Prague. 


\section{PLATE 1}

Frg. 1. Acute changes in the testicular tissue showing shrinkage of the central tubules. One tubule (indicated by arrow) has disintegrated completely, leaving a space ringed by interstitial tissue. $\times 46$.

Fig. 2. Mitotic figures in a portion of a seminiferous tubule. $\times 335$.

Frg. 3. Thickening of the nuclear membrane and clumping of the nuclear chromatin in a Leydig cell from a testis showing acute damage. $\times 1750$.

Fig. 4. Longitudinal section of ductuli efferentes showing proliferation and blockage within some of the ductuli (shown by arrows), proximal to which the tubules are dilated; a grossly enlarged lymphatic is shown in the upper part of the figure. Normal ductuli are visible in the bottom left-hand corner of the figure for comparison. $\times 36 \cdot 5$.

Fig. 5. Distortion of the tubules in the head of the epididymis produced by silver and cobalt. The initial segment (to the left of the figure) is relatively unaffected. $\times 36.5$.

Fig. 6. Severe chronic damage of seminiferous tubules. The cells appear darkly stained and poorly differentiated. The lumina are virtually obliterated, but the right tubule contains a condensed mass of spermatozoal tissue. $\times 135$.

Fig. 7. Vacuole produced by necrosis of Sertoli cell cytoplasm. The adjacent Sertoli cell nuclei (shown by arrows) appear swollen and granular. The surrounding spermatogenic cells are normal. $\times 750$.

\section{PLATE 2}

FIG. 8. Mild chronic damage in the seminiferous tubules, showing fragmentation of the tissues due to the disappearance of the Sertoli cell cytoplasm. The upper tubule contains pyknotic sperm heads but the others show slight spermatogenic activity. $\times 86$.

FIG. 9. Damaged Sertoli cell nucleus in the process of being extruded through the membrana propria (arrow). Neighbouring Sertoli cell nuclei appear to be moving towards the bulging membrane. $\times 610$.

Fic. 10. Breakdown of seminiferous tubules around the dilated central artery, with extrusion of their contents. $\times 86$.

FrG. 11. Distension of the rete testis resulting from necrosis of the ductuli efferentes. Oedema fluid is present in the dilated proximal ductuli efferentes. A seminiferous tubule (shown by arrow) is opening into the rete testis, which is seen to be continuous with the ductuli efferentes. $\times 36 \cdot 5$.

Fig. 12. Concentration of metal within the testis, shown by dark ground microscopy. The swollen membrana propria is shown by an arrow. One tubule shows the metal outlining the breaks in the tissue due to the disintegration of the Sertoli cell cytoplasm. $\times 196$.

Fig. 13. Metal accumulated in the body of the epididymis, in the spermatozoa within the ducts, and in the tubular walls. $\times 196$.

\section{PLATE 3}

Radiographs following $50 \%$ Micropaque injection. $\times 2 \cdot 9$.

Fig. 14. Silver: the vascular system of the testis is not well filled, but vessels draining the head and tail of the epididymis (arrows $X$ ) are well marked. Fairly large haemorrhages are visible in the fatty body, and the lymphatic drainage of the testis is grossly enlarged (arrow Y).

FIG. 15. Copper: the arterial system is more marked than with silver, and the venous drainage of the tail of the epididymis is visible, but that of the head is less prominent. A few small punctate haemorrhages are present in the fatty body.

FIG. 16. Tin: the vessels of both testis and epididymis are well filled and small haemorrhages occur in the fatty body. The lymphatic channel (arrow) is grossly distended.

Frg. 17. Cobalt: poor filling of the vascular system of the testis. Numerous small haemorrhages occur in the fatty body. Lymphatic drainage of the testis is grossly dilated (arrow). 
PLATE 1

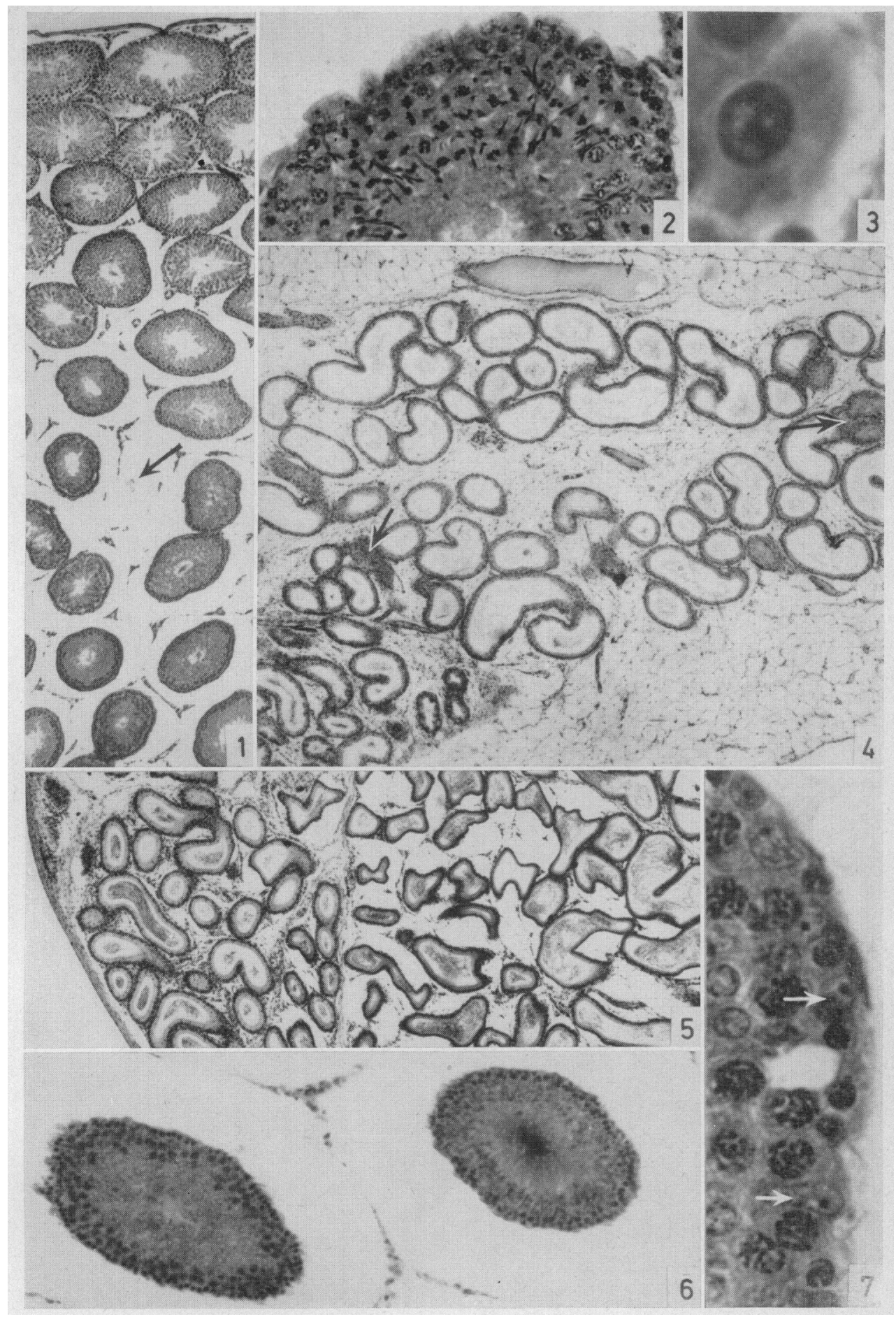

(Facing p. 472) 


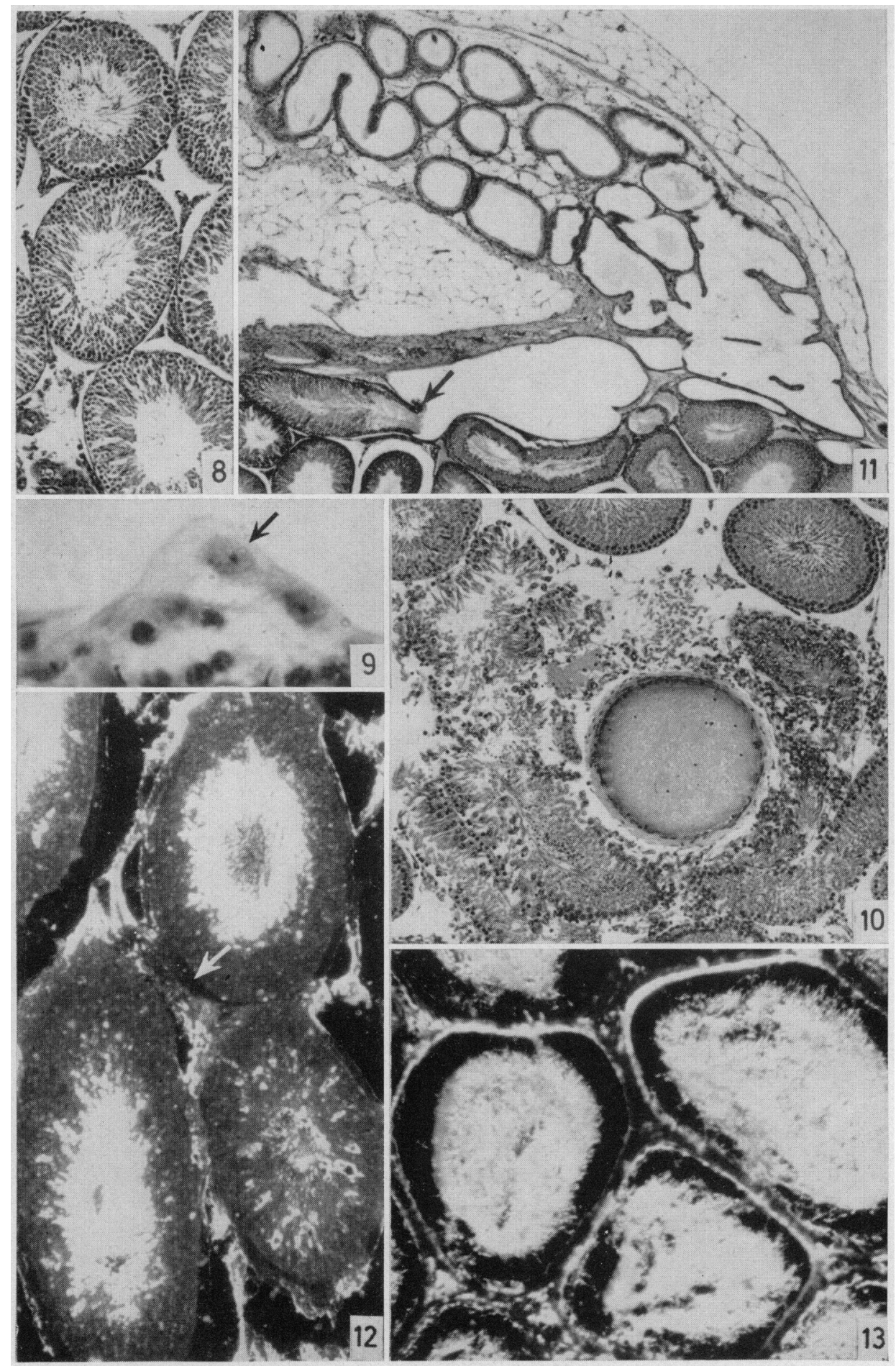


PLATE 3

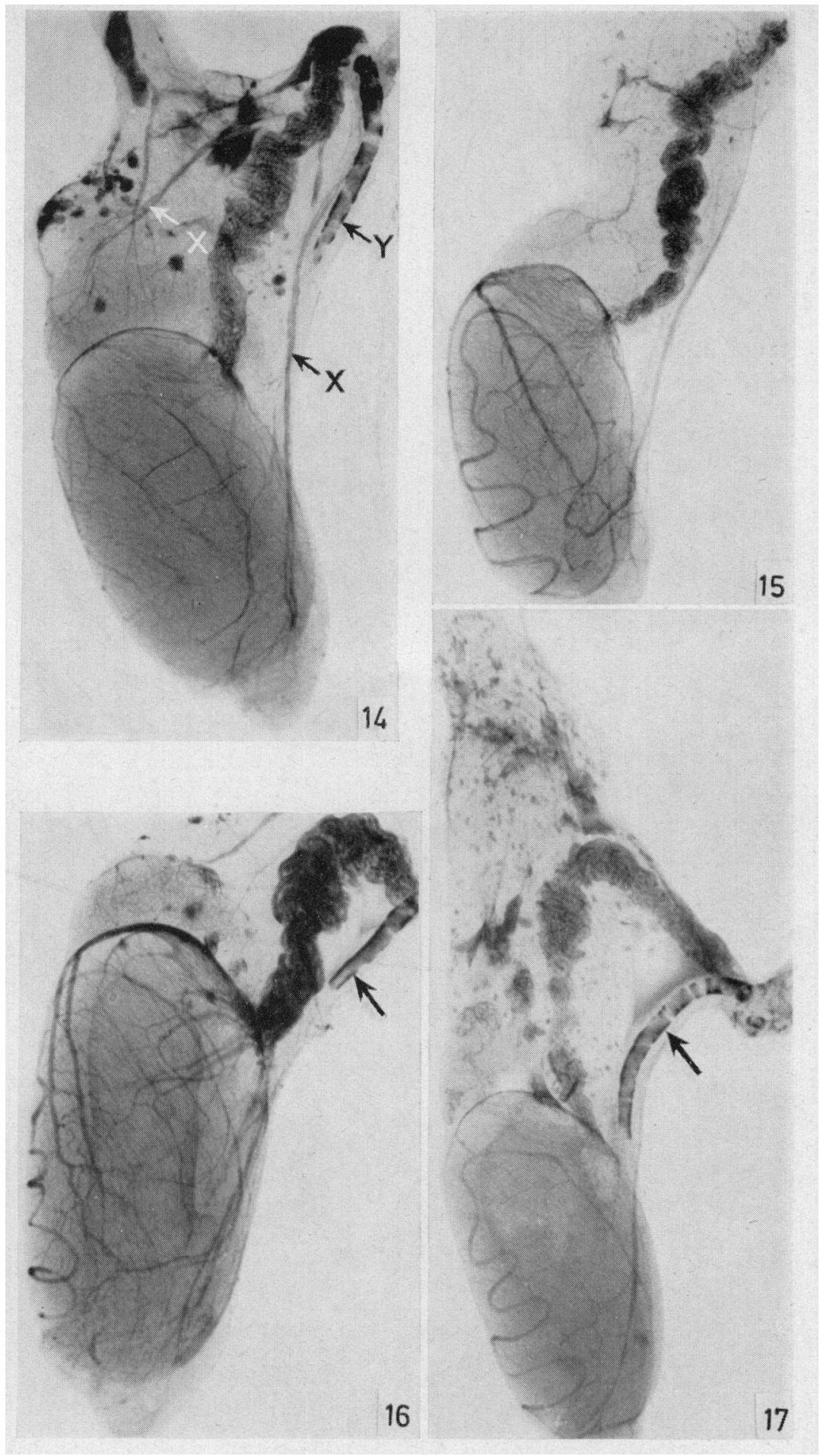

